\title{
Impact of renal dysfunction on long-term outcomes of elderly patients with acute coronary syndrome: a longitudinal, prospective observational study
}

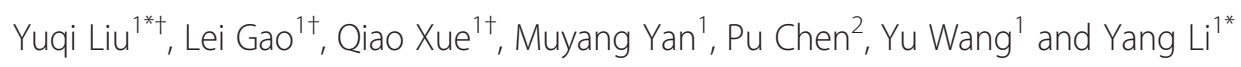

\begin{abstract}
Background: This study investigated the impact of renal dysfunction (RD) on long-term outcomes in elderly patients with acute coronary syndrome (ACS), and evaluated prognostic factors in elderly patients with ACS and RD.

Methods: This longitudinal prospective study included 184 consecutive patients who were admitted with ACS between January 2009 and January 2010 and also had RD. Patients were divided into five groups according to their estimated glomerular filtration rate (eGFR): 1) eGFR $\geq 90 \mathrm{~mL} / \mathrm{min} / 1.73 \mathrm{~m}^{2}$ with evidence of kidney damage, 2) $60 \leq$ eGFR $<90 \mathrm{~mL} / \mathrm{min} / 1.73 \mathrm{~m}^{2}$, 3) $30 \leq \mathrm{eGFR}<60 \mathrm{~mL} / \mathrm{min} / 1.73 \mathrm{~m}^{2}$, 4) $15 \leq \mathrm{eGFR}<30 \mathrm{~mL} / \mathrm{min} / 1.73 \mathrm{~m}^{2}$, and 5) eGFR $<$ $15 \mathrm{~mL} / \mathrm{min} / 1.73 \mathrm{~m}^{2}$. The primary endpoints were death and complications during hospitalization. The secondary endpoint was any major adverse cardiac event (MACE) during follow-up.
\end{abstract}

Results: The mean follow-up period was $502.2 \pm 203.6$ days. The mean patient age was $73.7 \pm 9.4$ years, and $61.4 \%$ of the patients were men. Severe RD (eGFR $\left.<30 \mathrm{~mL} / \mathrm{min} / 1.73 \mathrm{~m}^{2}\right)$ was an independent predictor of MACE. Severe $\mathrm{RD}$ was associated with a low hemoglobin level, low left ventricular ejection fraction, and high levels of highsensitivity C-reactive protein, N-terminal pro-B-type natriuretic peptide, and cystatin C. Survival was significantly poorer in patients with severe RD than in patients with mild RD.

Conclusions: Among patients with ACS, severe RD was associated with advanced age, diabetes, hypertension, and cardiac dysfunction. Severe RD was an independent risk factor for MACE, and was associated with poor prognosis.

Keywords: Acute coronary syndrome, Glomerular filtration rate, Renal dysfunction, MACE, Elderly

\section{Background}

Morbidity associated with chronic kidney disease (CKD) has increased with the growth of aging populations. CKD is strongly associated with increased mortality rate and accelerated cardiovascular disease (CVD) [1]. Patients with CKD have complex clinical conditions and a poor prognosis, and are difficult to treat [2-4]. One of the main concerns for patients with CKD is the increased risk of CVD, including coronary heart disease,

\footnotetext{
*Correspondence: ametuofo980869@163.com; liyangbsh@163.com ${ }^{\dagger}$ Equal contributors

'Institute of Geriatric Cardiology, Chinese PLA General Hospital, Beijing 100853, China

Full list of author information is available at the end of the article
}

cerebrovascular disease, and peripheral vascular disease [5-10]. A meta-analysis found that individuals with renal insufficiency have an approximately 3 -fold increased risk of CVD mortality compared with their counterparts without renal insufficiency [5]. Despite strong evidence linking CKD to poor outcomes, the impact of CKD on mortality and morbidity in elderly patients with acute coronary syndrome (ACS) is probably underappreciated, and elderly patients with CKD may not be treated as aggressively as patients with normal renal function. This study evaluated the impact of renal dysfunction (RD) on clinical outcomes including death, complications, and major adverse cardiac events (MACEs) in elderly patients with ACS. 


\section{Methods}

\section{Study population}

We analyzed the data of 184 consecutive elderly patients (all older than 60 years, mean age $73.7 \pm 9.4$ years, $61.4 \%$ men) who were admitted to our department with ACS between January 2009 and January 2010. All patients were discharged with a diagnosis of ACS based on cardiac enzyme levels and electrocardiography findings. Coronary angiography was performed in 129 patients. The secondary endpoint was analyzed in 147 patients, excluding 18 patients who were transferred to other hospitals or died, and 19 patients who were lost to followup. The ethics committee of the Chinese PLA General Hospital approved this study, and written informed consent for inclusion in the study was obtained from all subjects.

\section{Definitions}

The abbreviated Modification of Diet in Renal Disease formula was used to calculate the estimated glomerular filtration rate (eGFR) from the serum creatinine level [11]. Patients were divided into five groups according to their eGFR: Group I, eGFR $\geq 90 \mathrm{~mL} / \mathrm{min} / 1.73 \mathrm{~m}^{2}(\mathrm{n}=$ 13 , age $63.3 \pm 5.1$ years, $61.5 \%$ men); Group II, $60 \leq$ eGFR $<90 \mathrm{~mL} / \mathrm{min} / 1.73 \mathrm{~m}^{2}(\mathrm{n}=15$, age $65.2 \pm 7.4$ years, $73.3 \%$ men); Group III, $30 \leq \mathrm{eGFR}<60 \mathrm{~mL} / \mathrm{min} / 1.73 \mathrm{~m}^{2}$ $(\mathrm{n}=81$, age $76.0 \pm 7.6$ years, $69.2 \%$ men); Group IV, $15 \leq$ eGFR $<30 \mathrm{~mL} / \mathrm{min} / 1.73 \mathrm{~m}^{2}(\mathrm{n}=45$, age $74.3 \pm 8.7$ years, $53.3 \% \mathrm{men}$ ); and Group V, eGFR $\leq 15 \mathrm{~mL} / \mathrm{min} / 1.73 \mathrm{~m}^{2}$ ( $\mathrm{n}=30$, age $75.2 \pm 12.9$ years, $60 \%$ men).

Acute kidney injury is defined as a rapid reduction in renal function characterized by progressive azotemia (determined by the serum creatinine level), with or without oliguria. Acute kidney injury is categorized as Stage 1 if there is an increase in the serum creatinine level of $50 \%$ or $\geq 0.3 \mathrm{mg} / \mathrm{dL}$ within $48 \mathrm{~h}$, Stage 2 if there is an increase in the serum creatinine level of $\geq 100 \%$ (doubling), or Stage 3 if there is an increase in the serum creatinine level of $\geq 200 \%$ or of $0.5 \mathrm{mg} / \mathrm{dL}$ to at least $4.0 \mathrm{mg} / \mathrm{dL}$.

The primary endpoints were death and complications during hospitalization. The secondary endpoint was any MACE during the follow-up period, including cardiac death, myocardial infarction, stroke, and emergency or elective repeat revascularization. Cardiac death was defined as mortality not resulting from noncardiac disease.

The infarct-related artery was defined according to the American College of Cardiology/American Heart Association classification and the Thrombolysis In Myocardial Infarction flow grade [12]. Target lesion revascularization was defined as repeat revascularization with stenosis of $\geq 50 \%$ in the treated lesion. Target vessel revascularization was defined as repeat revascularization of the treated vessel. MACE was defined as any of cardiac death, myocardial infarction, target lesion revascularization, or target vessel revascularization. Other major bleeding was defined as severe bleeding other than intracranial bleeding. Death and complications during hospitalization were recorded, including cardiogenic shock, ventricular tachycardia or fibrillation requiring anti-arrhythmic drugs or defibrillation, atrioventricular block requiring temporary cardiac pacemaker insertion, recurrent myocardial ischemia or infarction, stroke, major bleeding, and acute kidney injury. If more than two complications occurred in a single patient, each complication type was recorded. After discharge, any MACEs during the follow-up period were recorded.

\section{Clinical data collection}

Laboratory data were collected on admission, including the levels of total cholesterol, low-density lipoprotein, hemoglobin, high-sensitivity C-reactive protein (hs-CRP), $\mathrm{N}$-terminal pro-B-type natriuretic peptide (NT-proBNP), serum creatinine, troponin- $\mathrm{T}$, creatine kinase- $\mathrm{MB}$, and cystatin $\mathrm{C}$ (Cys $\mathrm{C})$. Echocardiographic parameters were assessed by transthoracic echocardiography using the Teichholz method before coronary angiography, including thickness of the interventricular septum, left ventricular end-diastolic inner volume, left ventricular posterior wall thickness, and left ventricular ejection fraction.

\section{Statistical analysis}

Statistical analyses were performed using the Statistical Package for Social Sciences software (SPSS version 13.0). Continuous variables with normal distributions were expressed as mean \pm standard deviation and compared using 1-way analysis of variance. Categorical variables were compared using the chi-square test where appropriate. MACE was estimated by the unadjusted KaplanMeier method in the five eGFR groups. Cox proportional hazards modeling was used to examine the relationships between survival and a prespecified list of risk factors for MACE, including kidney function. The analyses were adjusted for hypertension, diabetes mellitus, smoking, sex, hyperlipidemia, age, hemoglobin level, surgical interventions, and medications (including aspirin, beta-blockers, angiotensin-converting enzyme inhibitors, calcium channel blockers, and statins).

\section{Results}

\section{Baseline characteristics}

A total of 184 patients were included in this study, including 13 (7.1\%) with ST-segment elevation myocardial infarction, $48(26.1 \%)$ with non-ST-segment elevation myocardial infarction, and 123 (66.8\%) with unstable angina. The median follow-up period was $502.2 \pm 203.6$ days. The mean patient age was $73.7 \pm 9.4$ years, and $61.4 \%$ of the patients were men. Patients with severe RD (eGFR < $30 \mathrm{~mL} / \mathrm{min} / 1.73 \mathrm{~m}^{2}$ ) had higher rates of comorbid conditions than those without severe $\mathrm{RD}$, including 
hypertension ( $\mathrm{n}=48,64.0 \%)$ diabetes mellitus ( $\mathrm{n}=48$, $64.0 \%)$, current smoking $(\mathrm{n}=25,33.3 \%)$, hyperlipidemia $(\mathrm{n}=15,20.0 \%)$, and a history of ischemic heart disease $(\mathrm{n}=44,58.6 \%)$. More severe RD was significantly associated with older age, hypertension, hyperlipidemia, ischemic heart disease, and high Killip class $(\mathrm{p}<0.05)($ Table 1$)$.

\section{Biochemical parameters and echocardiography findings}

Table 2 shows the baseline continuous variables. More severe RD was associated with a lower hemoglobin level, lower left ventricular ejection fraction, and higher levels of hs-CRP, NT-proBNP, and Cys C. The thickness of the interventricular septum, left ventricular end-diastolic inner volume, and left ventricular posterior wall thickness were greater in patients with severe RD than in patients with mild RD.

\section{Coronary angiography results}

Table 3 shows the coronary angiography data with different groups eGFR groups. A total of 129 (70.1\%) patients underwent coronary angiography. The number of involved vessels did not differ among the groups; patients with severe RD had more complex lesions in the left main coronary artery and in the infarct-related artery compared with the mild renal dysfunction group.

\section{Risk factors and outcomes}

Table 4 shows the in-hospital and out-of-hospital outcomes according to eGFR groups. In patients with normal renal function, the estimated in-hospital death rate was $0 \%$ and the estimated in-hospital complication rate was $7.7 \%$. Major bleeding occurred in one patient, who was in Group I. Cardiogenic shock occurred in five patients. Atrioventricular block occurred in four patients and ventricular tachycardia occurred in four patients, who were all in Group V. In patients with moderate RD, the in-hospital death rate $(3.9 \%)$ and the in-hospital complication rate $(20.6 \%)$ were significantly higher than in Group I (both $\mathrm{p}<0.05$ ). The incidence of MACE during follow-up was higher in Group V than in Group I $(\mathrm{p}<0.05)$. Figure 1 shows the Kaplan-Meier analyses for MACE-free survival during follow-up according to eGFR groups. Patients with severe RD had a lower probability of event-free survival than patients in the other groups. Cox multivariate regression analysis showed that eGFR was the main independent predictor of MACE (odds ratio 0.953, 95\% confidence interval 0.926-0.982, $\mathrm{p}=0.0004$ ).

Cox regression analysis of risk factors including eGFR showed that severe RD was an independent risk factor for MACE in patients with ACS, and was associated with poor prognosis. Anemia and statin drugs were also significantly associated with prognosis $(\mathrm{p}<0.05$, Table 5$)$.

\section{Discussion}

The results of recent studies of the relationships between CKD and mortality and morbidity after ACS suggest that severe $\mathrm{RD}$ is an independent predictor of cardiovascular events [13-15]. RD is directly or indirectly

Table 1 Baseline characteristics

\begin{tabular}{|c|c|c|c|c|c|c|}
\hline & Group I N = 13 & Group II N=15 & Group III N = 81 & Group IV N = 45 & Group V N = 30 & $P$ \\
\hline Age (yrs) & $63.3 \pm 5.1$ & $65.2 \pm 7.4$ & $76.0 \pm 7.6$ & $74.2 \pm 8.7$ & $75.2 \pm 12.9$ & 0.000 \\
\hline Male (\%) & $8(61.5)$ & $11(73.3)$ & $48(69.2)$ & $24(53.3)$ & $18(60.0)$ & NS \\
\hline $\mathrm{BMI}\left(\mathrm{kg} / \mathrm{m}^{2}\right)$ & $25.9 \pm 1.7$ & $27.3 \pm 5.2$ & $25.6 \pm 1.6$ & $23.8 \pm 2.9$ & $23.9 \pm 2.1$ & 0.000 \\
\hline \multicolumn{7}{|l|}{ Risk factor (\%) } \\
\hline Hypertension & $3(23.1)$ & $12(80.0)$ & $51(62.9)$ & $21(46.7)$ & $27(90.0)$ & 0.001 \\
\hline DM & $8(61.5)$ & $9(60.0)$ & $27(33.3)$ & $15(33.3)$ & $15(50.0)$ & NS \\
\hline Smoking & $3(23.1)$ & $5(33.3)$ & $19(23.5)$ & $17(37.7)$ & $8(26.7)$ & NS \\
\hline Hyperlipidemia & $8(61.5)$ & $9(60.0)$ & $18(22.2)$ & $6(13.3)$ & $9(30.0)$ & 0.0003 \\
\hline IHD & $3(23.1)$ & $7(46.7)$ & $30(37.0)$ & $22(48.9)$ & $22(73.3)$ & 0.005 \\
\hline \multicolumn{7}{|c|}{ Symptom at admission (\%) } \\
\hline Chest pain & $8(61.5)$ & $10(66 / 7)$ & $39(50.0)$ & $29(64.4)$ & $21(70.0)$ & NS \\
\hline Dyspnea & $0(0.0)$ & $1(6.7)$ & $5(6.4)$ & $3(6.7)$ & $2(6.7)$ & NS \\
\hline Killip class & $1.67 \pm 1.1$ & $1.67 \pm 1.2$ & $2.3 \pm 1.2$ & $2.5 \pm 1.1$ & $3.3 \pm 0.5$ & 0.000 \\
\hline Diagnosis & & & & & & NS \\
\hline UA & $8(61.5)$ & $11(73.3)$ & $54(6.7)$ & $27(60.0)$ & $21(70.0)$ & NS \\
\hline NSTEMI & $5(38.5)$ & $2(13.3)$ & $23(28.4)$ & 15 (33.3) & $6(20.0)$ & NS \\
\hline STEMI & $0(0)$ & $2(13.3)$ & $4(4.9)$ & $3(6.7)$ & $3(10.0)$ & NS \\
\hline
\end{tabular}

DM, diabetes mellitus; IHD, ischemic heart disease; STEMI, ST-segment elevation myocardial infarction; NSTEMI, non-ST-segment myocardial infarction; UA, unstable angina; NS, not significant. 
Table 2 Biochemical parameters and echocardiogram findings

\begin{tabular}{|c|c|c|c|c|c|c|}
\hline & Group I N = 13 & Group II N=15 & Group III N = 81 & Group IV N = 45 & Group V N = 30 & $P$ \\
\hline GFR (mL/min) & $106.8 \pm 9.2$ & $69.2 \pm 6.1$ & $42.9 \pm 9.4$ & $24.7 \pm 7.5$ & $10.9 \pm 3.4$ & 0.013 \\
\hline Creatinine (mg/dL) & $64.1 \pm 20.1$ & $103.0 \pm 19.4$ & $126.6 \pm 40.5$ & $331.4 \pm 148.4$ & $497.3 \pm 377.9$ & 0.003 \\
\hline Troponin T (ng/mL) & $0.12 \pm 0.10$ & $0.09 \pm 0.04$ & $0.41 \pm 0.33$ & $0.21 \pm 0.09$ & $0.59 \pm 0.49$ & 0.918 \\
\hline CK-MB (U/L) & $7.3 \pm 2.9$ & $9.9 \pm 3.6$ & $13.1 \pm 4.6$ & $13.2 \pm 3.7$ & $17.2 \pm 9.7$ & 0.627 \\
\hline $\mathrm{Hgb}(\mathrm{g} / \mathrm{dL})$ & $123.1 \pm 12.1$ & $135.8 \pm 13.9$ & $127.6 \pm 18.2$ & $107.1 \pm 23.7$ & $93.2 \pm 22.9$ & 0.000 \\
\hline $\mathrm{TC}(\mathrm{mmol} / \mathrm{L})$ & $3.6 \pm 1.2$ & $5.3 \pm 1.6$ & $4.3 \pm 1.1$ & $4.4 \pm 1.6$ & $3.4 \pm 0.9$ & 0.159 \\
\hline LDL-C (mmol/L) & $2.3 \pm 0.9$ & $2.9 \pm 1.2$ & $2.4 \pm 0.7$ & $2.5 \pm 1.3$ & $1.8 \pm 0.6$ & 0.257 \\
\hline hs-CRP (mg/dL) & $0.6 \pm 0.5$ & $1.1 \pm 0.7$ & $1.7 \pm 0.9$ & $2.7 \pm 1.2$ & $4.9 \pm 3.7$ & 0.000 \\
\hline Cys C (mg/l) & $0.6 \pm 0.3$ & $1.0 \pm 0.4$ & $1.4 \pm 0.5$ & $2.4 \pm 1.2$ & $3.7 \pm 2.8$ & 0.000 \\
\hline NT-proBNP (pg/mL) & $307.6 \pm 52.4$ & $1013.8 \pm 639.5$ & $4305.5 \pm 1054.5$ & $9687.3 \pm 3014.7$ & $10636.8 \pm 4016.9$ & 0.000 \\
\hline LVEF (\%) & $62 \pm 13$ & $53 \pm 13$ & $48 \pm 11$ & $49 \pm 10$ & $46 \pm 12$ & 0.007 \\
\hline IVS (mm) & $9.3 \pm 1.5$ & $10.8 \pm 1.8$ & $11.2 \pm 1.3$ & $11.9 \pm 1.4$ & $12.2 \pm 1.8$ & 0.021 \\
\hline LVPWT (mm) & $9.3 \pm 1.4$ & $11.4 \pm 2.3$ & $10.6 \pm 1.2$ & $11.2 \pm 1.7$ & $12.0 \pm 1.1$ & 0.028 \\
\hline EDV $(\mathrm{ml})$ & $48.0 \pm 3.0$ & $48.8 \pm 6.2$ & $49.4 \pm 5.9$ & $50.5 \pm 6.8$ & $56.2 \pm 5.6$ & 0.046 \\
\hline
\end{tabular}

GFR, glomerular filtration rate; Hgb, hemoglobin; TC, total cholesterol; LDL, low-density lipoprotein; hs-CRP, high-sensitivity C-reactive protein; NT-proBNP, N-terminal pro-B-type natriuretic peptide; CK-MB, creatine kinase-MB; NS, not significant; Cys C, cystatin C; LVEF, left ventricular ejection fraction; IVS, interventricular septal thickness; LVPWT, left ventricular posterior wall thickness; EDV, left ventricular end-diastolic inner volume.

Table 3 Baseline coronary angiographic findings

\begin{tabular}{|c|c|c|c|c|c|c|}
\hline & Group I $N=13$ & Group II N=15 & Group III N = 81 & Group IV N = 45 & Group V N $=30$ & $P$ \\
\hline CAG (\%) & $13(100)$ & $15(100)$ & $63(77.8)$ & $23(51.1)$ & $15(50)$ & 0.000 \\
\hline \multicolumn{7}{|c|}{ Infarct-related artery (\%) } \\
\hline LAD & $8(61.5)$ & $10(66.7)$ & $41(65.1)$ & $11(47.8)$ & $7(46.7)$ & 0.001 \\
\hline LCX & $1(7.7)$ & $1(6.7)$ & $7(11.1)$ & $3(13.0)$ & $1(6.7)$ & NS \\
\hline RCA & $4(30.8)$ & $3(20.0)$ & $13(20.6)$ & $7(30.4)$ & $4(26.7)$ & NS \\
\hline LM & $0(0)$ & $1(6.7)$ & $2(3.2)$ & $2(8.7)$ & $3(20.0)$ & NS \\
\hline \multicolumn{7}{|c|}{ Involved vessel number (\%) } \\
\hline 1 Branch & $7(53.8)$ & $8(53.3)$ & $23(36.5)$ & $11(47.8)$ & $5(33.3)$ & NS \\
\hline 2 branch & $4(30.8)$ & $4(26.7)$ & $32(50.8)$ & $7(30.4)$ & $3(20.0)$ & NS \\
\hline 3 branch & $2(15.4)$ & $2(13.3)$ & $7(11.1)$ & $2(8.7)$ & $4(26.7)$ & NS \\
\hline LM, isolated & $0(0)$ & $1(6.7)$ & $1(1.6)$ & $1(4.3)$ & $1(6.7)$ & NS \\
\hline LM, complex & $0(0)$ & $0(0)$ & $0(0)$ & $2(8.7)$ & $2(13.3)$ & 0.032 \\
\hline \multicolumn{7}{|c|}{ ACC / AHA classification } \\
\hline A & $7(53.8)$ & $5(33.3)$ & $21(33.3)$ & $2(8.7)$ & $3(20.0)$ & 0.045 \\
\hline B1 & $4(30.8)$ & $6(40.0)$ & $22(34.9)$ & $8(34.8)$ & $2(13.3)$ & NS \\
\hline B2 & $2(15.4)$ & $3(20.0)$ & $13(20.6)$ & $7(30.4)$ & $4(26.7)$ & NS \\
\hline C & $0(0)$ & $1(6.7)$ & $7(11.1)$ & $6(26.1)$ & $6(40.0)$ & 0.011 \\
\hline \multicolumn{7}{|l|}{ TIMI flow (\%) } \\
\hline TIMI 0 & $0(0)$ & $3(20.0)$ & $4(6.3)$ & $4(17.4)$ & $3(20.0)$ & NS \\
\hline TIMI 1 & $1(7.7)$ & $1(6.7)$ & $2(3.2)$ & $2(8.7)$ & $1(6.7)$ & NS \\
\hline TIMI 2 & $3(23.1)$ & $1(6.7)$ & $13(20.6)$ & $2(8.7)$ & $1(6.7)$ & NS \\
\hline TIMI 3 & $9(69.2)$ & $10(66.7)$ & $44(69.8)$ & $15(65.2)$ & $10(66.7)$ & NS \\
\hline
\end{tabular}

LM, left main; ACC/AHA, American College of Cardiology/American Heart Association; TIMI, thrombolysis in myocardial infarction; NS, not significant. 
Table 4 Outcomes according to estimated glomerular filtration rate

\begin{tabular}{|c|c|c|c|c|c|c|}
\hline & Group I N = 13 & Group II N=15 & Group III N= 81 & Group IV N = 45 & Group V N = 30 & $P$ \\
\hline \multicolumn{7}{|l|}{ In-hospital outcome } \\
\hline Death (\%) & 0 & $1(6.7)$ & $4(4.9)$ & $2(4.4)$ & $6(20)$ & 0.046 \\
\hline Complications (\%) & $1(7.7)$ & $1(6.7)$ & $5(6.7)$ & $4(8.8)$ & $8(26.7)$ & 0.031 \\
\hline AKI & 0 & $1(6.7)$ & $2(2.5)$ & $1(2.2)$ & $2(6.7)$ & NS \\
\hline Cardiogenic shock & 0 & $1(6.7)$ & $2(2.5)$ & $4(8.8)$ & $5(16.7)$ & NS \\
\hline Major bleeding & $1(7.7)$ & 0 & $1(1.2)$ & $1(2.2)$ & $1(3.3)$ & NS \\
\hline AV block & 0 & 0 & $1(1.2)$ & $2(4.4)$ & $4(13.3)$ & 0.039 \\
\hline VT & 0 & 0 & $1(1.2)$ & $2(4.4)$ & $4(13.3)$ & 0.039 \\
\hline Hospital stay (days) & $10.3 \pm 10.9$ & $19.8 \pm 11.9$ & $19.9 \pm 18.8$ & $24.5 \pm 28.1$ & $29.1 \pm 12.5$ & 0.042 \\
\hline \multicolumn{7}{|c|}{ Out-hospital outcome } \\
\hline MACE (\%) & $1(7.7)$ & $2(13.3)$ & $7(8.6)$ & $5(11.1)$ & $10(33.3)$ & 0.015 \\
\hline Cardiac death & 0 & 0 & $1(1.2)$ & $2(4.4)$ & $2(6.7)$ & NS \\
\hline Ml & 0 & $1(6.7)$ & $1(1.2)$ & $2(4.4)$ & $5(16.7)$ & 0.016 \\
\hline $\mathrm{Re}-\mathrm{PCl}$ & $1(7.7)$ & $2(26.7)$ & $3(3.7)$ & $4(8.9)$ & $4(13.3)$ & NS \\
\hline TVR & $1(7.7)$ & $2(13.3)$ & $1(1.2)$ & $2(4.4)$ & $2(6.7)$ & NS \\
\hline Non-TVR & 0 & $1(6.7)$ & $1(1.2)$ & $1(2.2)$ & $1(3.3)$ & NS \\
\hline TLR & 0 & $1(6.7)$ & $1(1.2)$ & $1(2.2)$ & $1(3.3)$ & NS \\
\hline CABG & 0 & $1(6.7)$ & 00 & $1(2.2)$ & $1(3.3)$ & NS \\
\hline Stroke & $1(7.7)$ & 0 & 0 & $1(2.2)$ & $2(6.7)$ & NS \\
\hline
\end{tabular}

AKI, acute kidney injury; VT, ventricular tachycardia; MACE, major adverse cardiac event; PCl, percutaneous coronary intervention; TVR, target vessel revascularization; TLR, target lesion revascularization; MI, myocardial infarction; CABG, coronary artery bypass graft; NS, not significant.

involved in the development of hypertension, hyperlipidemia, endothelial disorders, and neuroendocrine disorders, which are all important contributors to the further advancement of RD in patients with ACS [4]. The American Kidney Foundation guidelines state that the prevalence of coronary heart disease increases with decreasing eGFR. A decrease in GFR to $<60 \mathrm{~mL} / \mathrm{min} /$ $1.73 \mathrm{~m}^{2}$ is an independent risk factor for coronary heart disease [16]. In this study, patients with more severe RD had higher mortality after ACS and were more likely to have hypertension, hyperlipidemia, ischemic heart disease, and cardiac dysfunction. Coronary angiography is relatively contraindicated in these patients. Surgeons should assess preoperative renal function and adequately

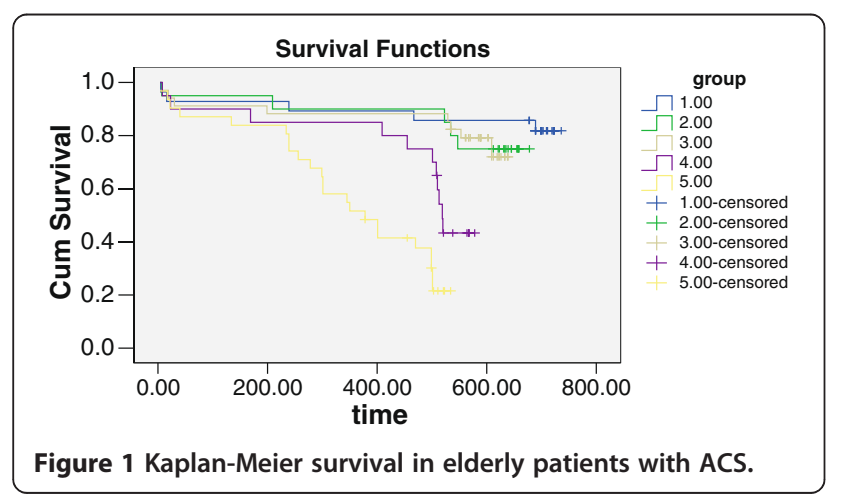

communicate with patients and their families about the risks of angiography. It is important to ensure adequate hydration before and after coronary angiography, perform dialysis as needed, and prevent contrast-induced nephropathy and further damage to renal function. Patients with more severe RD undergo less frequent coronary angiography. Evaluation of renal function is an important aspect of risk assessment in patients with ACS. Current biomarkers of early changes in renal function include microalbuminuria and decreased eGFR [17].

Many patients become progressively malnourished as renal function decreases. The resulting decreases in albumin, prealbumin, and transferrin levels activate the inflammatory cascade $[18,19]$. Several aspects of progressive renal failure cause changes in plasma composition and endothelial structure and function that favor vascular injury [20-22]. However, the mechanisms underlying the impact of $\mathrm{RD}$ on the prognosis after ACS remain unclear. Significantly elevated serum levels of interleukin-6, CRP, and tumor necrosis factor- $\alpha$ have been observed in patients with renal failure, but no differences in prognosis have been reported between patients who underwent long-term dialysis and those who did not. In patients with CKD, the prevalences of vascular disease and malnutrition-inflammation-atherosclerosis syndrome increase as renal function decreases. Comorbidities may contribute to these changes [22,23]. Elevated inflammatory 


\begin{tabular}{|c|c|c|}
\hline Factors & Hazard ratio $(95 \% \mathrm{Cl})$ & $P$ \\
\hline Mild RD (eGFR $\left.\geqq 90 \mathrm{~mL} / \mathrm{min} / 1.73 \mathrm{~m}^{2}\right)$ & 1.000 & \\
\hline $\begin{array}{l}\text { Moderate RD } \\
\left(30 \leqq e G F R<90 \mathrm{~mL} / \mathrm{min} / 1.73 \mathrm{~m}^{2}\right)\end{array}$ & $0.892(0.506 \sim 1.781)$ & 0.393 \\
\hline $\begin{array}{l}\text { Severe RD } \\
\left(15 \leqq e G F R<30 \mathrm{~mL} / \mathrm{min} / 1.73 \mathrm{~m}^{2}\right)\end{array}$ & $1.983(1.014 \sim 5.543)$ & 0.034 \\
\hline $\begin{array}{l}\text { Renal failure } \\
\left(\mathrm{eGFR}<15 \mathrm{~mL} / \mathrm{min} / 1.73 \mathrm{~m}^{2}\right)\end{array}$ & $2.724(1.051 \sim 6.955)$ & 0.021 \\
\hline Hypertension & $1.218(0.371 \sim 3.995)$ & 0.745 \\
\hline DM & $1.971(0.622 \sim 6.241)$ & 0.249 \\
\hline Smoke & $1.000(0.975 \sim 1.026)$ & 0.973 \\
\hline Sex & $0.658(0.229 \sim 1.894)$ & 0.438 \\
\hline Hyperlipidemia & $0.392(0.060 \sim 2.564)$ & 0.329 \\
\hline Stroke & $0.161(0.015 \sim 1.701)$ & 0.129 \\
\hline Age & $1.014(0.958 \sim 1.073)$ & 0.632 \\
\hline Anemia & $0.113(0.019 \sim 0.666)$ & 0.016 \\
\hline \multicolumn{3}{|l|}{ Medications } \\
\hline Aspirin & $1.083(0.316 \sim 3.719)$ & 0.899 \\
\hline B-blocker & $2.181(0.734 \sim 6.479)$ & 0.161 \\
\hline ACEI/ARB & $1.871(0.624 \sim 5.611)$ & 0.264 \\
\hline CCB & $1.255(0.470 \sim 3.356)$ & 0.650 \\
\hline Statins & $0.258(0.080 \sim 0.835)$ & 0.024 \\
\hline
\end{tabular}

ACEl: Angiotensin-converting enzyme inhibitors, ARB: Angiotensin II receptor antagonists, CCB: Calcium channel blocker.

cytokine levels are associated with increased risk of cardiovascular disease $[24,25]$. The results of this study confirmed that severe RD is associated with high levels of inflammatory cytokines such as hs-CRP, but the cytokine levels were not independent predictors of MACE. Cys C is an independent predictor of early RD [26]. Our results also show higher Cys $\mathrm{C}$ levels in patients with more severe RD. Severe anemia and RD were independent risk factors for MACE, which is consistent with the results of previous studies $[27,28]$.

The term "renal senescence" refers to a series of physiological and structural changes resulting in decreased renal function in aging individuals. Our findings are consistent with earlier reports that healthy individuals aged over 60 years have a GFR 20 to 30\% lower than in individuals aged less than 50 years. The percentage of globally sclerosed glomeruli is frequently 10 to $40 \%$ in 60-year-old patients $[29,30]$, which results in functional glomerulopenia. Sclerosis of the juxtamedullary glomeruli of aging patients results in a vascular connection between afferent and efferent arterioles that maintains an adequate rate of medullary blood flow while shunting blood past the obsolescent glomeruli. Elderly patients often have high morbidity associated with hypertension, diabetes mellitus, and other diseases, leading to the development of glomerular sclerosis. The elderly are also prone to RD due to stress or adverse drug effects, and such RD is difficult to reverse. Additionally, the prevalences of coronary heart disease and $\mathrm{RD}$ gradually increase with age. Evaluation of the risk factors and long-term prognosis of elderly patients with coronary heart disease and RD is therefore important. Our findings confirmed that in patients with ACS, more severe $\mathrm{RD}$ is associated with older age, hypertension, hyperlipidemia, and poor cardiac function. During follow-up, the incidence of MACE was significantly higher in patients with severe RD than in patients with mild RD. In patients with ACS, severe RD is an independent predictor of MACE and is associated with poor long-term prognosis. Evaluation of risk factors, overall renal function, and treatment options is therefore very important in patients with ACS.

This study has some limitations that should be discussed. First, the proportion of patients with unstable angina is higher in this study than that of previously reported studies. The American College of Cardiology/ American Heart Association guidelines suggest that approximately $37 \%$ of patients with ACS have unstable angina [31]. We believe that the high proportion of patients with unstable angina may be attributed to the fact that the majority of patients were Beijing residents. It would therefore be useful for these patients to attend regular medical examinations, enabling earlier diagnosis and treatment. Second, 19 patients were lost to follow-up. Some of these patients lived in remote areas, with poor access to transport and communication media. Some patients may also have relocated during the relatively long follow-up period. Finally, patients with more severe RD underwent coronary angiography less frequently. This may be because RD is a relative contraindication to coronary angiography. Acute deterioration in renal function due to administration of contrast medium is a well-recognized complication after coronary angiography, particularly in patients with pre-existing CKD. We also considered these procedures in the multivariate Cox analysis.

\section{Conclusions}

Among patients with ACS, severe RD was associated with advanced age, diabetes, hypertension, and cardiac dysfunction. Severe RD was an independent risk factor for MACE, and was associated with poor prognosis.

\section{Abbreviations}

ACS: Acute coronary syndrome; RD: Renal dysfunction; eGFR: Estimated glomerular filtration rate; MACEs: Major adverse cardiac events; CKD: Chronic kidney disease; CVD: Cardiovascular disease; AKI: Acute kidney injury; SCr: Serum creatinine; NT-proBNP: N-terminal pro-B-type natriuretic peptide; hs-CRP: Highsensitivity C-reactive protein; Cys C: Cystatin C; ACC/AHA: The American College of Cardiology and the American Heart Association; STEMI: ST segment elevation myocardial infarction; NSTEMI: Non-ST Segment Elevation Myocardial Infarction; UA: Unstable angina; ACS: Acute coronary syndrome. 


\section{Competing interests}

All of authors declare that they have no competing interests.

\section{Authors' contributions}

Y. Liu, LG, and QX carried out the statistical analysis and drafted the manuscript. YF, JG, and XY collected the clinical data. MY, Y. Li, and YW participated in the design of the study and performed the statistical analysis. SW conceived of the study and participated in its design and coordination. All authors read and approved the final manuscript.

\section{Acknowledgments}

This work was supported by grants from the National Science Foundation of China to YL (no: 81030002) and YQ Liu (no: 81100186/H0214). The authors thank Dr. Yichen Fu and Dr. Jinliao Gao for their contributions to the study design, data acquisition, and data analysis.

\section{Author details}

${ }^{1}$ Institute of Geriatric Cardiology, Chinese PLA General Hospital, Beijing 100853, China. ${ }^{2}$ Kidney Department, Chinese PLA General Hospital, Beijing 100853, China.

Received: 1 October 2012 Accepted: 12 March 2014

Published: 9 May 2014

\section{References}

1. Sarnak MJ, Levey AS, Schoolwerth AC, Coresh J, Culleton B, Hamm LL, McCullough PA, Kasiske BL, Kelepouris E, Klag MJ, Parfrey P, Pfeffer M, Raij L, Spinosa DJ, Wilson PW: American Heart Association Councils on Kidney in Cardiovascular Disease, High Blood Pressure Research, Clinical Cardiology, and Epidemiology and Prevention. Kidney disease as a risk factor for development of cardiovascular disease: a statement from the American Heart Association Councils on Kidney in Cardiovascular Disease, High Blood Pressure Research, Clinical Cardiology, and Epidemiology and Prevention. Hypertension 2003, 42:1050-1065.

2. Bonaca MP, Steg PG, Feldman LJ, Canales JF, Ferguson JJ, Wallentin L, Califf RM, Harrington RA, Giugliano RP: Antithrombotics in acute coronary syndromes. J Am Coll Cardiol 2009, 54(11):969-984.

3. Theroux P: Perspectives on acute coronary syndromes. Can J Cardiol 2005, 21(11):1053-1060.

4. Feit F, Voeltz MD, Attubato MJ, Lincoff AM, Chew DP, Bittl JA, Topol EJ, Manoukian SV: Predictors and impact of major hemorrhage on mortality following percutaneous coronary intervention from the REPLACE-2 Trial. Am J Cardiol 2007, 100(9):1364-1369.

5. Tonelli M, Wiebe N, Culleton B, House A, Rabbat C, Fok M, McAlister F, Garg AX: Chronic kidney disease and mortality risk: a systematic review. J Am Soc Nephrol 2006, 17(7):2034-2047.

6. Muntner P, He J, Hamm L, Loria C, Whelton PK: Renal insufficiency and subsequent death resulting from cardiovascular disease in the United States. J Am Soc Nephrol 2002, 13(3):745-753.

7. Guruprasad M, Hocine T, Hassan I, Bonnie ML, Salem DN, Griffith JL, Josef C, Levey AS, Sarnak MJ: Level of kidney function as a risk factor for atherosclerotic cardiovascular outcomes in the community. J Am Coll Cardiol 2003, 41(1):47-55.

8. Anavekar NS, McMurray JJ, Velazquez EJ, Solomon SD, Kober L, Rouleau JL, White HD, Nordlander R, Maggioni A, Dickstein K, Zelenkofske S, Leimberger JD, Califf RM, Pfeffer MA: Relation between renal dysfunction and cardiovascular outcomes after myocardial infarction. N Engl J Med 2004, 351(13):1285-1295.

9. Go AS, Chertow GM, Fan D, McCulloch CE, Hsu CY: Chronic kidney disease and the risks of death, cardiovascular events, and hospitalization. $N$ Engl $J$ Med 2004, 351(13):1296-1305.

10. Weiner DE, Tighiouart $H$, Amin MG, Stark PC, MacLeod B, Griffith UL, Salem DN, Levey AS, Sarnak MJ: Chronic kidney disease as a risk factor for cardiovascular disease and all-cause mortality: a pooled analysis of community-based studies. J Am Soc Nephrol 2004, 15(5):1307-1315.

11. Levey AS, Coresh J, Greene T, Stevens LA, Zhang YL, Hendriksen S, Kusek JW, Van Lente F, Chronic Kidney Disease Epidemiology Collaboration: Using standardized serum creatinine values in the modification of diet in renal disease study equation for estimating glomerular filtration rate. Ann Intern Med 2006, 145(4):247-254.

12. Roberts WL, Moulton L, Law TC, Farrow G, Cooper-Anderson M, Savory J, Rifai N: Evaluation of nine automated high-sensitivity C-reactive protein methods: implications for clinical and epidemiological applications: Part 2. Clin Chem 2001, 47(3):418-425.
13. Eikelboom JW1, Anand SS, Mehta SR, Weitz JI, Yi C, Yusuf S: Effects of recombinant hirudin (lepirudin) compared with heparin on death, myocardial infarction, refractory angina, and revascularisation procedures in patients with acute myocardial ischaemia without ST elevation: a randomised trial. Lancet 1999, 353(9151):429-438.

14. Rao AK, Pratt C, Berke A, Jaffe A, Ockene I, Schreiber TL, Bell WR, Knatterud G, Robertson TL, Terrin ML: Thrombolysis In Myocardial Infarction (TIMI) trialphase I: hemorrhagic manifestations and changes in plasma fibrinogen and the fibrinolytic system in patients treated with recombinant tissue plasminogen activator and streptokinase. J Am Coll Cardiol 1988, 76(I1):1-11.

15. The GUSTO Investigators: An international randomized trial comparing four thrombolytic strategies for acute myocardial infarction. N Engl J Med 1993, 329(18):673-682.

16. Rao SV, Jollis JG, Harrington RA, Granger CB, Newby LK, Armstrong PW, Moliterno DJ, Lindblad L, Pieper K, Topol EJ, Stamler JS, Califf RM: Relationship of blood transfusion and clinical outcomes in patients with acute coronary syndromes. JAMA 2004, 292(13):1555-1562

17. Yang X, Alexander KP, Chen AY, Roe MT, Brindis RG, Rao SV, Gibler WB, Ohman EM, Peterson ED, CRUSADE Investigators: The implications of blood transfusions for patients with non-ST-segment elevation acute coronary syndromes: results from the CRUSADE National Quality Improvement Initiative. J Am Coll Cardiol 2005, 46(8):1490-1495.

18. Kalantar-Zadeh K, Ikizler TA, Block G, Avram MM, Kopple JD: Malnutritioninflammation complex syndrome in dialysis patients: causes and consequences. Am J Kidney Dis 2003, 42(5):864-881.

19. Qureshi AR, Alvestrand A, Danielsson A, Divino-Filho JC, Gutierrez A Lindholm B, Bergström J: Factors predicting malnutrition in hemodialysis patients: a cross-sectional study. Kidney Int 1998, 53(3):773-782.

20. Kaysen GA, Eiserich JP: The role of oxidative stress-altered lipoprotein structure and function and microinflammation on cardiovascular risk in patients with minor renal dysfunction. J Am Soc Nephrol 2004, 15(3):538-548.

21. Pecoits-Filho R, Heimbürger O, Bárány P, Suliman M, Fehrman-Ekholm I, Lindholm B, Stenvinkel P: Associations between circulating inflammatory markers and residual renal function in CRF patients. Am J Kidney Dis 2003, 41(6):1212-1218.

22. Ross R: Atherosclerosis-an inflammatory disease. N Engl J Med 1999, 340(2):115-126.

23. Schiffrin EL, Lipman ML, Mann JF: Chronic kidney disease: effects on the cardiovascular system. Circulation 2007, 116(1):85-97.

24. Shlipak MG, Fried LF, Cushman M, Manolio TA, Peterson D, Stehman-Breen C, Bleyer A, Newman A, Siscovick D, Psaty B: Cardiovascular mortality risk in chronic kidney disease: comparison of traditional and novel risk factors. JAMA 2005, 293(14):1737-1745.

25. Menon V, Greene T, Wang X, Pereira AA, Marcovina SM, Beck GJ, Kusek JW Collins AJ, Levey AS, Sarnak MJ: C-reactive protein and albumin as predictors of all-cause and cardiovascular mortality in chronic kidney disease. Kidney Int 2005, 68(2):766-772.

26. Shlipak MG, Praught ML, Sarnak MJ: Update on cystatin C: new insights into the importance of mild kidney dysfunction. Curr Opin Nephrol Hypertens 2006, 15(3):270-275.

27. Walker AM, Schneider G, Yeaw J, Nordstrom B, Robbins S, Pettitt D: Anemia as a predictor of cardiovascular events in patients with elevated serum creatinine. J Am Soc Nephrol 2006, 17(8):2293-2298.

28. Keough-Ryan TM, Kiberd BA, Dipchand CS, Cox JL, Rose CL, Thompson KJ, Clase CM: Outcomes of acute coronary syndrome in a large Canadian cohort: impact of chronic renal insufficiency, cardiac interventions, and anemia. Am J Kidney Dis 2005, 46(5):845-855.

29. Hoang K, Tan JC, Derby G, Blouch KL, Masek M, Ma I, Lemley KV, Myers BD: Determinants of glomerular hypofiltration in aging humans. Kidney Int 2003, 64(4):1417-1724.

30. GlassockR J, Winearls C: Ageing and the glomerular filtration rate: truths and consequences [J]. Trans Am Clin Climatol Assoc 2009, 120:419-428.

31. Pope JH, Ruthazer R, Beshansky JR, Griffith JL, Selker HP: Clinical features of emergency department patients presenting with symptoms suggestive of acute cardiac ischemia: a multicenter study [J]. J Thromb Thrombolysis 1998, 6(1):63-74.

doi:10.1186/1471-2369-15-78

Cite this article as: Liu et al:: Impact of renal dysfunction on long-term outcomes of elderly patients with acute coronary syndrome: a longitudinal, prospective observational study. BMC Nephrology 2014 15:78. 